\title{
Effect of anxiety and depression on the fatigue of patients with a permanent pacemaker
}

Maria Polikandrioti ${ }^{1}$, Konstantinos Tzirogiannis ${ }^{2}$, Sofia Zyga ${ }^{3}$, Ioannis Koutelekos ${ }^{1}$, Georgios Vasilopoulos ${ }^{1}$, Paraskevi Theofilou ${ }^{4}$, George Panoutsopoulos ${ }^{2}$

\author{
${ }^{1}$ Faculty of Health and Caring Professions, Department of Nursing, Technological \\ Educational Institute, Athens, Greece \\ 2Laboratory of Physiology and Pharmacology, Department of Nursing, \\ Faculty of Human Movement and Quality of Life Sciences, University of Peloponnese, \\ Sparta Lakonias, Greece \\ ${ }^{3}$ Department of Nursing, Faculty of Human Movement and Quality of Life Sciences, \\ University of Peloponnese, Sparta Lakonias, Greece \\ ${ }^{4}$ Department of Psychology, Health Psychology, Panteion University, Athens, Greece
}

Submitted: 5 December 2017

Accepted: 30 December 2017

Arch Med Sci Atheroscler Dis 2018; 3: e8-e17

DOI: https://doi.org/10.5114/amsad.2018.73231

Copyright @ 2018 Termedia \& Banach

\section{Abstract}

Introduction: Permanent cardiac pacemakers (PPM) are the most common treatment for severe symptomatic bradycardia. This implanted life-saving device may involve a severe psychological burden to recipients or aggravate their symptoms such as fatigue. The aim of the study was to explore the effect of anxiety and depression on fatigue of patients' with a PPM.

Material and methods: The study group consisted of 250 patients with a PPM. Data collected included: a) patients' characteristics, b) the Hospital Anxiety and Depression Scale (HADS) and c) the Fatigue Assessment Scale (FAS).

Results: High levels of anxiety and depression were observed in $27.2 \%$ and $14.0 \%$ of the sample, respectively. Regarding the fatigue total score it was found that $25 \%$ of the participants had a score higher than 26 . Accordingly, with regard to physical and mental fatigue, $25 \%$ of enrolled patients had a score higher than 20 and 8 , respectively. These values indicate moderate to low levels of fatigue. Furthermore, there was a statistically significant association between anxiety/depression and the total score of fatigue as well as between anxiety/depression and physical and mental fatigue $(p<0.001$ for all associations).

Conclusions: Socio-demographic and patients' clinical characteristics are related to anxiety and depression. Understanding the association between psychological burden and fatigue after implantation as well as factors associated with these variables will help health professionals to provide beneficial care for PPM patients that will significantly contribute to better device outcomes.

Key words: fatigue, anxiety-depression, pacemaker implantation.

\section{Introduction}

A cardiac pacemaker is a small medical device implanted to maintain an adequate heart rate [1]. According to global estimates, the annual implantation rate is 600 thousand pacemakers while 3 million individuals already have a pacemaker [2]. During the last 30 years, implantation rates have increased 2.7-fold [3], mainly due to the more accurate diagnosis of coronary disease, to the ageing of population and to the

\author{
Corresponding author: \\ Prof. Maria Polikandrioti \\ Faculty of Health \\ and Caring Professions \\ Department of Nursing \\ Technological \\ Educational Institute \\ Ag. Spyridon 28, Aigaleo \\ 12242 Athens, Greece \\ Phone: +331 6972425054 \\ E-mail: mpolik2006@yahoo. \\ com
}


improvement of devices that are currently available $[3,4]$.

Nowadays, the life expectancy of recipients with no significant comorbidities almost equals that of the general population $[5,6]$. Therefore, several goals of cardiac rehabilitation have emerged, such as optimizing patients' medical treatment, enhancing psychological well-being and improving health-related quality of life $[5,6]$. Interestingly, the device may save recipients from life-threatening arrhythmia, but at the same time, it is life-changing, implying several challenges in the process of psychosocial adaptation [7]. Not surprisingly, the intrusiveness of a foreign device in the heart, which symbolizes the center of emotions, is frequently associated with psychological distress [8]. Indeed, recipients encounter various physical, financial and social problems including restriction of activities and the feeling of living with the pacemaker [2].

Despite the considerable progress in understanding patients' psychological state, data on pacemaker patients are sparse. Additionally, no studies are available on how important these measurements are with respect to levels of fatigue. It is well known that psychiatric problems and in particular depression go together with fatigue in those undergoing health care. This disabling combination negatively affects the outcome of a chronic disease [9].

Thus, this cross-sectional study was carried out to determine the effect of anxiety and depression on fatigue of permanent cardiac pacemaker patients and explore the associated factors.

\section{Material and methods}

\section{Study population}

The sample of the study consisted of 250 patients who had a pacemaker (160 men and 90 women). This sample was a convenience sample.

Data were collected in the outpatient departments of two public hospitals that patients were visiting for regular monitoring and follow-up. Criteria for inclusion in the study were: a) implantation of a pacemaker, b) the ability to write and read the Greek language fluently, and c) adequate follow-up. The exclusion criteria were patients: a) with a history of mental illness and b) with a serious chronic disease.

Data collection was performed via an interview using a questionnaire developed by the researchers so as to fully serve the purposes of the study. The data collected for each patient included: socio-demographic characteristics (e.g. gender, age, education level), clinical characteristics (e.g. when the symptoms had started), therapy characteristics (e.g., adherence to treatment guidelines), and other patients' characteristics.
Completion of the questionnaires lasted approximately 15 min and took place when patients attended their regular monitoring and follow-up.

In the present study there was no intervention or control group since this research merely recorded whether patients experienced anxiety and depression and their impact on fatigue as it was reported by patients. For this reason, we used Hospital Anxiety and Depression Scale (HADS), which is widely used to determine the levels of anxiety and depression that a patient is experiencing, as well as the Fatigue Assessment Scale (FAS), which is commonly used to determine fatigue. Literature on this association was limited, thus not enabling extensive comparative research.

\section{Ethical considerations}

Patients who met the entry criteria were informed by the researcher for the purposes of the study and participated only after they had given their written consent. All of the patients participated in the study on a voluntary basis and had their anonymity preserved. All participants were informed of their rights to refuse or to discontinue their participation, according to the ethical standards of the Helsinki Declaration of 1983. The study was approved by the Medical Research Ethics Committee of each hospital.

\section{Assessment of anxiety and depression}

Patients' mental health (depression and anxiety) was examined by the evaluation of HADS, which was proposed by Zigmond and Snaith [10]. The scale consists of 14 questions that assess how patients felt during the previous week. Patients are able to answer every question on a 4-point Likert scale from 0 to 3 . Seven of the 14 questions assess the level of depression and the other seven evaluate the anxiety level. The scores attributed to questions are summed up separately for anxiety and depression, leading to two scores ranging between 0 and 21 . Higher scores indicate increased levels of anxiety or depression. In addition, the following categorization has been proposed and is widely used in scientific papers: score $0-7$ indicating no anxiety or depression, score 8-10 indicating moderate levels of anxiety or depression, and score $>11$ indicating high levels of anxiety or depression. The HADS scale has been translated and tested for its validity and reliability in the Greek population [11].

\section{Assessment of fatigue}

The fatigue of patients with a pacemaker was evaluated by the FAS. The scale collects information related to the perceived fatigue in the Greek population and has an internal consistency of 0.761 [12]. The scale consists of 10 questions that assess the 
fatigue of patients on a Likert type scale (scores from 1 to 5$)$. The coding of responses is as follows: $1=$ never, 2 = sometimes, 3 = regularly, 4 = often, $5=$ always. Therefore, the score ranges between 10 and 50. Five questions are related to physical fatigue and the other five to mental fatigue. The score is summed up separately for the questions that assess physical fatigue, and separately for those that assess mental fatigue and all questions. Both scores are then added together to represent the total fatigue. Higher values of scores indicate increased fatigue [12].

\section{Statistical analysis}

Categorical data are presented as absolute and relative (\%) frequencies, whereas continuous data are presented as the median (interquartile range). The Kruskal-Wallis test was used to test the association between fatigue and a factor with more than two categories, while the Mann-Whitney test was performed to access the association between fatigue and a factor with two categories. Spearman's rho correlation coefficient was used to evaluate the association between fatigue and patient characteristics. The $\chi^{2}$ test of independence was used to evaluate the association between levels of anxiety/depression and patients' characteristics. Moreover, multiple linear regression was carried out to estimate the effect of anxiety/ depression on fatigue. Results are presented as the regression coefficient ( $\beta$-coefficient) and 95\% confidence interval $(95 \% \mathrm{Cl})$. The level of statistical significance was set to $\alpha=5 \%$. All statistical analyses were performed using the SPSS version 20 package (SPSS Inc, Chicago, II, USA).

\section{Results}

\section{Sample description}

Men accounted for $64 \%$ of the sample, while half of the subjects were over 71 years of age (median).

Table I. Patients' demographics $(N=250)$

\begin{tabular}{|lc|}
\hline Parameter & $N(\%)$ \\
\hline Gender (male) & $160(64.0)$ \\
\hline \begin{tabular}{lc} 
Education: \\
\hline Secondary school
\end{tabular} & $120(48.0)$ \\
\hline $\begin{array}{l}\text { University } \\
\text { MSc-PhD }\end{array}$ & $20(32.0)$ \\
\hline No education & $1(11.6)$ \\
\hline Parameter & Median (IQR) \\
\hline Age [years] & $71(59-78)$ \\
\hline
\end{tabular}

Out of the 250 patients, $48 \%$ had primary school education and in 50\% the pacemaker had been implanted under the age of 66 (median). Skin infection due to the pacemaker occurred in $8.9 \%$ of the patients. At least one symptom occurred after the insertion of the pacemaker in $14 \%$, with the most common symptom being redness of the skin at the site of incision (6.4\%). Furthermore, 69.6\% considered themselves anxious while around $20 \%$ of the sample were "very" anxious about their heart rate and the functioning of the device. Half of the patients had someone else who helped them in their everyday activities (52.4\%) while $63.6 \%$ believed that their life depended on health professionals to a large degree. Almost all the participants believed that the pacemaker solved their arrhythmia $(94.8 \%)$ and $50.8 \%$ that their quality of life was improved significantly. Finally, $17.6 \%$ continued smoking after the pacemaker implantation and $44.4 \%$ did not exercise at all (Tables I-III).

\section{Levels of anxiety and depression}

Table IV presents the results concerning the levels of anxiety and depression of patients with a pacemaker. The results showed that $59.2 \%$ and $67.2 \%$ of patients reported low levels of anxiety and depression, respectively. High levels of anxiety and depression were observed in $27.2 \%$ and $14.0 \%$ of the sample, respectively.

Table II. Patients' clinical characteristics $(N=250)$

\begin{tabular}{|c|c|}
\hline Variable & $N(\%)$ \\
\hline $\begin{array}{l}\text { Has your skin over the pacemaker } \\
\text { ever been infected? (Yes) }\end{array}$ & $22(8.9)$ \\
\hline \multicolumn{2}{|c|}{$\begin{array}{l}\text { Which of the following symptoms have you felt after } \\
\text { the placement of the pacemaker? }\end{array}$} \\
\hline $\begin{array}{l}\text { Skin redness at the pacemaker's } \\
\text { incision }\end{array}$ & $16(6.4)$ \\
\hline Breathing difficulty & $4(1.6)$ \\
\hline Vertigo or fainting & $11(4.4)$ \\
\hline $\begin{array}{l}\text { Aggravated weakness and } \\
\text { fatigue }\end{array}$ & $3(1.2)$ \\
\hline Chest pain & $1(0.4)$ \\
\hline Swelling in the legs or hands & $3(1.2)$ \\
\hline Fever & $9(3.6)$ \\
\hline $\begin{array}{l}\text { Reappearance of symptoms that } \\
\text { occurred before the pacemaker } \\
\text { was placed }\end{array}$ & $7(2.8)$ \\
\hline At least 1 of the above & $35(14.0)$ \\
\hline Variable & Median (IQR) \\
\hline Age when pacemaker was placed & $66(56-73)$ \\
\hline Years having the pacemaker & $4(2-6)$ \\
\hline
\end{tabular}


Table III. Patients' other characteristics $(N=250)$

\begin{tabular}{|c|c|}
\hline Variable & $N(\%)$ \\
\hline Do you consider yourself anxious? (Yes) & $174(69.6)$ \\
\hline \multicolumn{2}{|c|}{ Do you have anxiety about your heart rate disorder? } \\
\hline Severe & $58(23.2)$ \\
\hline Moderate & $47(18.8)$ \\
\hline A little & $65(26.0)$ \\
\hline None & $80(32.0)$ \\
\hline \multicolumn{2}{|c|}{$\begin{array}{l}\text { Do you have anxiety about the proper function of the } \\
\text { implanted device? }\end{array}$} \\
\hline Severe & $49(19.6)$ \\
\hline Moderate & $52(20.8)$ \\
\hline A little & $61(24.4)$ \\
\hline None & $88(35.2)$ \\
\hline $\begin{array}{l}\text { Do you have someone who helps you } \\
\text { in your everyday activities? (Yes) }\end{array}$ & $131(52.4)$ \\
\hline \multicolumn{2}{|l|}{$\begin{array}{l}\text { Do you believe your life depends on health } \\
\text { professionals? }\end{array}$} \\
\hline Greatly & $159(63.6)$ \\
\hline Moderately & $87(34.8)$ \\
\hline Not at all & $4(1.6)$ \\
\hline $\begin{array}{l}\text { Do you think that the pacemaker solves } \\
\text { the problem of arrhythmia? (Yes) }\end{array}$ & $237(94.8)$ \\
\hline \multicolumn{2}{|c|}{ Has your quality of life improved after the placement? } \\
\hline Greatly & $127(50.8)$ \\
\hline Moderately & $99(39.6)$ \\
\hline A little & $23(9.2)$ \\
\hline Not at all & $1(0.4)$ \\
\hline Do you smoke after the placement? (Yes) & $44(17.6)$ \\
\hline \multicolumn{2}{|l|}{ Do you exercise after the placement? } \\
\hline A lot & $13(5.2)$ \\
\hline Moderately & $41(16.4)$ \\
\hline A little & $85(34.0)$ \\
\hline Not at all & $111(44.4)$ \\
\hline
\end{tabular}

\section{Fatigue}

As far as fatigue is concerned, at least $50 \%$ of the patients' scores were found to be below 19 (median) of the total score, whereas the physical and mental fatigue were found to be below 15 and 4, respectively (Table IV). Regarding the total score, it was found that $25 \%$ of the participants had a score higher than 26 . Accordingly, with regard to the physical and mental fatigue, $25 \%$ of enrolled patients had a score higher than 20 and 8 ,
Table IV. Levels of anxiety and depression of patients with a pacemaker and their fatigue score

\begin{tabular}{|lc|}
\hline Variable & $\boldsymbol{N}(\%)$ \\
\hline Levels of anxiety: & $148(59.2)$ \\
\hline Low & $34(13.6)$ \\
\hline High & $68(27.2)$ \\
\hline Levels of depression: & $169(67.2)$ \\
\hline Low & $47(18.8)$ \\
\hline Moderate & $35(14.0)$ \\
\hline High & Median (IQR) \\
\hline Variable & $19(15-26)$ \\
\hline Total score of fatigue (range: 10-50) & $15(11-20)$ \\
\hline Physical fatigue (range: $7-35)$ & $4(3-8)$ \\
\hline Mental fatigue (range: 3-15) & \\
\hline
\end{tabular}

respectively. These values indicate moderate to low levels of fatigue.

\section{Characteristics associated with anxiety and depression}

Tables V and VI present the statistically significant associations between patients' characteristics and the levels of anxiety and depression, respectively.

Regarding anxiety, women more frequently suffered high levels of anxiety $(40 \%)$ than men $(20 \%$, $p<0.001)$. Likewise, high levels of anxiety were observed more frequently in patients with primary school education $(29.8 \%, p=0.020)$ and those who considered themselves anxious $(37.9 \%, p=$ 0.001 ) or were very anxious about their heart rate (56.2\%, $p=0.001$ ) and the proper functioning of their device $(57.4 \%, p=0.001)$. Furthermore, patients who had someone helping them in their everyday activities more frequently experienced high levels of anxiety (33.6\%, $p=0.021)$, and this was the case with patients who believed that their life depended on health professionals (34\%, $p=0.008)$ or those who did not believe that the pacemaker solved the problem $(92.3 \%, p=0.001)$ or did not think that their quality of life was improved $(66.7 \%, p=0.001)$. Moreover, patients who did not smoke after the insertion of the pacemaker and those who had experienced symptoms had high levels of anxiety more frequently $(29.1 \%, p=$ 0.021 and $48.6 \%, p=0.009$ ). Finally, patients with high levels of anxiety had the pacemaker fitted for less time (median 3 years, $p=0.011$ ) than those with low (median 4 years) and moderate levels (median 4 years). 
Table V. Characteristics associated with anxiety levels

\begin{tabular}{|c|c|c|c|c|}
\hline Parameter & $\begin{array}{c}\text { Low levels } \\
\text { of anxiety } \\
N(\%)\end{array}$ & $\begin{array}{c}\text { Moderate levels } \\
\text { of anxiety } \\
N(\%)\end{array}$ & $\begin{array}{c}\text { High levels } \\
\text { of anxiety } \\
N(\%)\end{array}$ & $P$-value \\
\hline Gender: & & & & $<0.001$ \\
\hline Male & $112(70.0)$ & $16(10.0)$ & $32(20.0)$ & \\
\hline Female & $36(40.0)$ & $18(20.0)$ & $36(40.0)$ & \\
\hline Education: & & & & 0.020 \\
\hline Primary school & $63(52.1)$ & $22(18.2)$ & $36(29.8)$ & \\
\hline Secondary school & $47(58.8)$ & $11(13.8)$ & $22(27.5)$ & \\
\hline University & $38(77.6)$ & $1(2.0)$ & $10(20.4)$ & \\
\hline Do you consider yourself anxious? & & & & 0.001 \\
\hline Yes & $79(45.4)$ & $29(16.7)$ & $66(37.9)$ & \\
\hline No & $69(90.8)$ & $5(6.6)$ & $2(2.6)$ & \\
\hline Do you have anxiety about your heart rate disorder? & & & & 0.001 \\
\hline A lot/moderate & $34(32.4)$ & $12(11.4)$ & $59(56.2)$ & \\
\hline A little/not at all & $114(78.6)$ & $22(15.2)$ & $9(6.2)$ & \\
\hline $\begin{array}{l}\text { Do you have anxiety about the proper function of the } \\
\text { implanted device? }\end{array}$ & & & & 0.001 \\
\hline A lot/moderate & $31(30.7)$ & $12(11.9)$ & $58(57.4)$ & \\
\hline A little/not at all & $117(78.5)$ & $22(14.8)$ & $10(6.7)$ & \\
\hline $\begin{array}{l}\text { Do you have someone who helps you in your everyday } \\
\text { activities? }\end{array}$ & & & & 0.021 \\
\hline Yes & $67(51.1)$ & $20(15.3)$ & $44(33.6)$ & \\
\hline No & $81(68.1)$ & $14(11.8)$ & $24(20.2)$ & \\
\hline $\begin{array}{l}\text { Do you believe your life depends on health } \\
\text { professionals? }\end{array}$ & & & & 0.008 \\
\hline Greatly & $87(54.7)$ & $18(11.3)$ & $54(34.0)$ & \\
\hline Moderately & $57(65.5)$ & $16(18.4)$ & $14(16.1)$ & \\
\hline $\begin{array}{l}\text { Do you think that the pacemaker solves the problem } \\
\text { of arrhythmia? }\end{array}$ & & & & 0.001 \\
\hline Yes & $148(62.4)$ & $33(13.9)$ & $56(23.6)$ & \\
\hline No & $0(0.0)$ & $1(7.7)$ & $12(92.3)$ & \\
\hline Has your quality of life improved after the placement? & & & & 0.001 \\
\hline A lot & $90(70.9)$ & $8(6.3)$ & $29(22.8)$ & \\
\hline Moderately & $53(53.5)$ & $23(23.2)$ & $23(23.2)$ & \\
\hline A little/not at all & $5(20.8)$ & $3(12.5)$ & $16(66.7)$ & \\
\hline Do you smoke after the placement? & & & & 0.021 \\
\hline Yes & $34(77.3)$ & $2(4.5)$ & $8(18.2)$ & \\
\hline No & $114(55.3)$ & $32(15.5)$ & $60(29.1)$ & \\
\hline Symptoms after the placement & & & & 0.009 \\
\hline Yes & $15(42.9)$ & $3(8.6)$ & $17(48.6)$ & \\
\hline No & $133(61.9)$ & $31(14.4)$ & $51(23.7)$ & \\
\hline Parameter & Median (IQR) & Median (IQR) & Median (IQR) & $P$-value \\
\hline Age [years] & $72(56-78)$ & $70(4-80)$ & $70(58-78)$ & 0.579 \\
\hline Age when pacemaker was placed & $66(53-72)$ & $67(62-73)$ & $66(56-73)$ & 0.476 \\
\hline Years having the pacemaker & $4(2-6)$ & $4(2-5)$ & $3(1-5)$ & 0.011 \\
\hline
\end{tabular}


Table VI. Characteristics associated with depression levels

\begin{tabular}{|c|c|c|c|c|}
\hline Parameter & $\begin{array}{c}\text { Low levels } \\
\text { of depression } \\
N(\%)\end{array}$ & $\begin{array}{c}\text { Moderate } \\
\text { levels } \\
\text { of depression } \\
N(\%)\end{array}$ & $\begin{array}{c}\text { High levels } \\
\text { of depression } \\
N(\%)\end{array}$ & $P$-value \\
\hline Gender: & & & & 0.002 \\
\hline Male & $120(75.0)$ & $23(14.4)$ & $17(10.6)$ & \\
\hline Female & $48(53.3)$ & $24(26.7)$ & $18(20.0)$ & \\
\hline Education: & & & & 0.023 \\
\hline Primary school & $76(62.8)$ & $23(19.0)$ & $22(18.2)$ & \\
\hline Secondary school & $50(62.5)$ & $18(22.5)$ & $12(15.0)$ & \\
\hline University & $42(85.7)$ & $6(12.2)$ & $1(2.0)$ & \\
\hline Do you consider yourself anxious? & & & & 0.001 \\
\hline Yes & $104(59.8)$ & $38(21.8)$ & $32(18.4)$ & \\
\hline No & $64(84.2)$ & $9(11.8)$ & $3(3.9)$ & \\
\hline Do you have anxiety about your heart rate disorder? & & & & 0.001 \\
\hline A lot/moderate & $51(48.6)$ & $29(27.6)$ & $25(23.8)$ & \\
\hline A little/not at all & $117(80.7)$ & $18(12.4)$ & $10(6.9)$ & \\
\hline $\begin{array}{l}\text { Do you have anxiety about the proper function of the } \\
\text { device? }\end{array}$ & & & & 0.001 \\
\hline A lot/moderate & $49(48.5)$ & $28(27.7)$ & $24(23.8)$ & \\
\hline A little/not at all & $119(79.9)$ & $19(12.8)$ & $11(7.4)$ & \\
\hline $\begin{array}{l}\text { Do you have someone who helps you in your everyday } \\
\text { activities? }\end{array}$ & & & & 0.001 \\
\hline Yes & $72(55.0)$ & $32(24.4)$ & $27(20.6)$ & \\
\hline No & $96(80.7)$ & $15(12.6)$ & $8(6.7)$ & \\
\hline $\begin{array}{l}\text { Do you think that the pacemaker solves the problem } \\
\text { of arrhythmia? }\end{array}$ & & & & 0.001 \\
\hline Yes & $168(70.9)$ & $43(18.1)$ & $26(11.0)$ & \\
\hline No & $0(0.0)$ & $4(30.8)$ & $9(69.2)$ & \\
\hline Has your quality of life improved after the placement? & & & & 0.001 \\
\hline A lot & $102(80.3)$ & $11(8.7)$ & $14(11.0)$ & \\
\hline Moderately & $64(64.6)$ & $28(28.3)$ & $7(7.1)$ & \\
\hline A little/Not at all & $2(8.3)$ & $8(33.3)$ & $14(58.3)$ & \\
\hline Do you smoke after the placement? & & & & 0.003 \\
\hline Yes & $39(88.6)$ & $4(9.1)$ & $1(2.3)$ & \\
\hline No & $129(62.6)$ & $43(20.9)$ & $34(16.5)$ & \\
\hline Do you exercise after the placement? & & & & 0.001 \\
\hline A lot/moderately & $42(77.8)$ & $10(18.5)$ & $2(3.7)$ & \\
\hline A little & $69(81.2)$ & $11(12.9)$ & $5(5.9)$ & \\
\hline Not at all & $57(51.4)$ & $26(23.4)$ & $28(25.2)$ & \\
\hline Symptoms after the placement: & & & & 0.001 \\
\hline Yes & $13(37.1)$ & $11(31.4)$ & $11(31.4)$ & \\
\hline No & $155(72.1)$ & $36(16.7)$ & $24(11.2)$ & \\
\hline Parameter & Median (IQR) & Median (IQR) & Median (IQR) & $P$-value \\
\hline Age [years] & $72(57-78)$ & $69(60-80)$ & $75(59-80)$ & 0.226 \\
\hline Age when pacemaker was placed & $66(53-72)$ & $66(58-74)$ & $70(57-76)$ & 0.138 \\
\hline Years having the pacemaker & $4(2-6)$ & $3.5(1.5-5)$ & $2(2-5)$ & 0.034 \\
\hline
\end{tabular}


Regarding depression, women experienced high levels of depression more frequently (20\%) than men $(10.6 \%, p=0.002)$. Similarly, high levels of depression were observed more frequently in patients with primary school education $(18.2 \%$, $p=0.023)$ and those who considered themselves anxious $(18.4 \%, p=0.001)$ or were very anxious about their heart rate $(23.8 \%, p=0.001)$ and the proper functioning of their device $(23.8 \%$, $p=0.001)$. Furthermore, patients who had someone helping them in their everyday activities were prone to high levels of depression more frequently $(20.6 \%, p=0.001)$, and this was also the case among patients who did not believe that the pacemaker solved the problem $(69.2 \%, p=0.001)$ or did not think that their quality of life was improved $(58.3 \%, p=0.001)$. Moreover, patients who did not smoke after pacemaker implantation, those who did not exercise at all and those who had experienced symptoms suffered high levels of depression (16.5\%, $p=0.003,25.2 \%, p=0.001$ and $31.4 \%$, $p=0.001$ respectively) more frequently. Lastly, patients with high levels of depression had had the pacemaker a median of 2 years, which differed significantly $(p=0.034)$ from those with low (median 4 years) and moderate levels (median 3.5 years).

\section{Association between fatigue and levels of anxiety/depression}

Table VII presents the results of the association of fatigue and levels of anxiety/depression. From the results, there was a statistically significant association between anxiety/depression and the total score of fatigue as well as in physical and mental fatigue ( $p<0.001$ for all associations). To be specific, patients with high levels of anxiety and depression felt more fatigue.

\section{Effect of anxiety/depression on fatigue}

In order to assess the effect of anxiety/depression on fatigue, multiple linear regression was performed which was adjusted to various potential confounding factors affecting fatigue. From Table VIII it was concluded that after adjustment for confounders there was a significant reduction in the effect of anxiety/depression on fatigue ( $\beta$-coefficients were reduced $>10 \%$ ).

Furthermore, patients with moderate levels of anxiety had 5.77 (95\% Cl: 3.72-7.85, $p<0.001)$ points higher in the total fatigue, $3.55(95 \% \mathrm{Cl}$ : 2.01-5.10, $p<0.001)$ points higher in the physical fatigue and $2.22(95 \% \mathrm{Cl}: 1.43-3.01, p<0.001)$ points higher in the mental fatigue score than patients with low levels of anxiety after adjusting for confounding factors. Also, patients with high levels of anxiety had 10.55 (95\% Cl: 8.48-12.62, $p<0.001)$ points higher in total fatigue, 6.36 (95\% Cl: 4.81-7.90, $p<0.001$ ) points higher in physical fatigue and $4.16(95 \% \mathrm{Cl}$ : 3.37-4.95, $p<0.001)$ points higher in mental fatigue than patients with low levels of anxiety.

Regarding depression, similarly as above, patients with moderate levels of depression had 6.73 (95\% Cl: 4.78-8.69, $p<0.001$ ) points higher in total fatigue, 4.07 (95\% Cl: $2.65-5.48, p<0.001)$ points higher in physical fatigue and $2.60(95 \% \mathrm{Cl}$ : $1.81-3.38, p<0.001)$ points higher in mental fatigue than patients with low levels of depression after adjusting for confounding factors. Furthermore, patients with high levels of depression had 11.40 (95\% Cl: 9.03-13.77, $p<0.001)$ points higher in total fatigue, $7.74(95 \% \mathrm{Cl}: 6.02-9.45$, $p<0.001)$ points higher in physical fatigue and 3.70 (95\% Cl: 2.72-4.66, $p<0.001)$ points higher in mental fatigue than patients with low levels of depression.

\section{Study limitations}

The results should be interpreted with caution as they are limited by the method of convenience sampling. This method is not reprehensive of all patients in Greece, thus limiting the generalizabil-

Table VII. Association between fatigue and levels of anxiety/depression

\begin{tabular}{|c|c|c|c|c|c|c|}
\hline Variable & $\begin{array}{l}\text { Total fatigue } \\
\text { median (IQR) }\end{array}$ & $P$-value & $\begin{array}{l}\text { Physical fatigue } \\
\text { median (IQR) }\end{array}$ & $P$-value & $\begin{array}{c}\text { Mental fatigue } \\
\text { median (IQR) }\end{array}$ & $P$-value \\
\hline \multicolumn{7}{|c|}{ Levels of anxiety: } \\
\hline Low & $16(13-19)^{\star}$ & $<0.001$ & $12(10-15)^{\star}$ & $<0.001$ & $3(3-4)^{*}$ & $<0.001$ \\
\hline Moderate & $24.5(20-27)$ & & $18(14-20)$ & & $6(5-8)$ & \\
\hline High & $29(25-36)$ & & $21(18-26)$ & & $8(7-9)$ & \\
\hline \multicolumn{7}{|c|}{ Levels of depression: } \\
\hline Low & $17(14-19)^{*}$ & $<0.001$ & $13(10-16)^{*}$ & $<0.001$ & $3(3-4)^{*}$ & $<0.001$ \\
\hline Moderate & $26(24-31)$ & & $20(18-22)$ & & $8(6-9)$ & \\
\hline High & $36(28-38)$ & & $26(20-29)$ & & $9(8-11)$ & \\
\hline
\end{tabular}

*Statistically significantly different score compared to the rest of the categories, after Bonferroni correction. 
Table VIII. Effect of anxiety/depression on fatigue

\begin{tabular}{|c|c|c|c|c|c|c|}
\hline Variable & $\begin{array}{c}\text { Total fatigue } \\
\beta \text { coef. }(95 \% \mathrm{Cl})\end{array}$ & $P$-value & $\begin{array}{l}\text { Physical fatigue } \\
\beta \text { coef. }(95 \% \mathrm{Cl})\end{array}$ & $P$-value & $\begin{array}{l}\text { Mental fatigue } \\
\beta \text { coef. }(95 \% \mathrm{Cl})\end{array}$ & $P$-value \\
\hline \multicolumn{7}{|l|}{ Crude regression } \\
\hline \multicolumn{7}{|c|}{ Levels of anxiety: } \\
\hline Low & Ref. category & & Ref. category & & Ref. category & \\
\hline Moderate & $8.79(6.61-10.98)$ & $<0.001$ & $5.76(4.11-7.40)$ & $<0.001$ & $3.03(2.26-3.79)$ & $<0.001$ \\
\hline High & $13.02(11.31-14.72)$ & $<0.001$ & $8.57(7.28-9.85)$ & $<0.001$ & $4.40(3.80-4.99)$ & $<0.001$ \\
\hline \multicolumn{7}{|c|}{ Levels of depression: } \\
\hline Low & Ref. category & & Ref. category & & Ref. category & \\
\hline Moderate & $9.73(7.92-11.55)$ & $<0.001$ & $6.27(4.95-7.59)$ & $<0.001$ & $3.40(2.72-4.08)$ & $<0.001$ \\
\hline High & $16.03(14.01-18.05)$ & $<0.001$ & $11.21(9.74-12.69)$ & $<0.001$ & $4.81(4.04-5.57)$ & $<0.001$ \\
\hline \multicolumn{7}{|c|}{ Adjusted regression* } \\
\hline \multicolumn{7}{|c|}{ Levels of anxiety: } \\
\hline Low & Ref. category & & Ref. category & & Ref. category & \\
\hline Moderate & $5.77(3.72-7.85)$ & $<0.001$ & $3.55(2.01-5.10)$ & $<0.001$ & $2.22(1.43-3.01)$ & $<0.001$ \\
\hline High & $10.55(8.48-12.62)$ & $<0.001$ & $6.36(4.81-7.90)$ & $<0.001$ & $4.16(3.37-4.95)$ & $<0.001$ \\
\hline \multicolumn{7}{|c|}{ Levels of depression: } \\
\hline Low & Ref. category & & Ref. category & & Ref. category & \\
\hline Moderate & $6.73(4.78-8.69)$ & $<0.001$ & $4.07(2.65-5.48)$ & $<0.001$ & $2.60(1.81-3.38)$ & $<0.001$ \\
\hline High & $11.40(9.03-13.77)$ & $<0.001$ & $7.74(6.02-9.45)$ & $<0.001$ & $3.70(2.72-4.66)$ & $<0.001$ \\
\hline
\end{tabular}

${ }^{\star}$ Regression adjusted to the following factors: gender, age, educational level, degree of information, whether patients consider themselves anxious, whether patients have anxiety about their heart rate or the proper function of the device, whether patients have someone who helps, whether patients think that the pacemaker solves the problem of arrhythmia, how much the quality of life was improved, whether patients smoke or exercise after the placement and whether they experienced any symptoms.

ity of results. Also, the study was cross sectional and collected data at one point in time, thus not allowing determination of the causal relation between anxiety-depression and fatigue after device implantation or exploration of changes over time.

\section{Discussion}

In the present study the majority of participants were men. Similar observations were made in Germany [1] and in the U.S. [13], with $52.7 \%$ and $52.8 \%$ of participants respectively being male. In Zurich out of a total of 70 participants, 50 were male and 26 female [8]. According to the results, $27.2 \%$ and $14.0 \%$ of participants experienced high levels of anxiety and depression, respectively. In clinical settings, the value of this finding is not merely to compare it with other relevant studies but to enhance awareness about psychological distress among health care professionals, who usually pay more attention to technical aspects of the device [8]. However, a similar observation was made in a prior survey which showed that $10.7 \%$ of pacemaker patients were clinically depressed [14]. Cardiac illness may be a chronic burden that triggers a depressive episode as it changes the individual's sense of purpose and meaning in life $[15,16]$.

Data of the present study revealed high levels of anxiety and depression in women, and in patients with primary education. These findings are in line with Vellone et al., who indicated that less educated individuals and those having low income were more vulnerable to anxiety and depression [4]. Similarly, Aydemir et al. [14] found that the severity of depression was significantly higher in females while uneducated patients had a significant loss of energy. Meanwhile, the role of gender in the endorsement of psychopathology is well known. For example, women are different regarding family or social roles, heritability or vulnerability, personality traits, biological risk, and other mechanisms [17-20].

Higher levels of anxiety were experienced by participants who reported dependency on health professionals. The association between anxiety and dependency on health professionals has seldom been the subject of systematic enquiry. Nevertheless, device implantation typically in- 
volves a short hospital stay, although treatment success demands regular and long-term follow-up to assess device functioning or any other practical aspects [21]. Therefore, clinical settings should encourage scheduled visits to emphasize patient responsibility in the therapeutic regimen and support self-efficacy behaviors [21, 22]. Interestingly, $20 \%$ of recipients request support group participation [8].

Data also revealed high levels of anxiety and depression in patients who considered themselves anxious, or were very anxious about heart rate, the proper functioning of the device and those who did not believe that the device solves the problem of arrhythmia. To the best of our knowledge, these findings have been rarely addressed in previous studies. Hence, it is crucial to know which patient-related characteristics have true value when assessing the occurrence of anxiety and depression. Nevertheless, the psychological burden needs deep exploration whether it is attributed to the lack of knowledge or doubts about the therapeutic effect. Adopting the model of participatory decision making, health professionals should co-operate with patients and their families to ensure that they understand the context of this arrhythmia management device [7]. Patients who have not acquired sufficient knowledge may confront many hazards [21-23].

In support of this view there is evidence that patients may impose unnecessary restrictions on routine activities (driving, climbing stairs, using the arm of the implantation side, use of a microwave oven) especially when they perceive them as a threat to the proper functioning of the device [24]. Data illustrate the need for future research to identify other types of interventions (telephone follow-up or internet use) to maintain the acquired knowledge of pacemaker-related issues [16, 21]. Finally and more strikingly, patients reporting themselves as anxious may perceive all the necessary changes in life including restrictions imposed by the device as a threat [25].

According to the current data, patients with high levels of anxiety and depression felt more fatigue. Data referring to psychiatric disorders and fatigue among patients with a pacemaker are limited in both national and international scientific research and several issues remain obscure. However, the association between fatigue and anxiety or depression seems to be a vicious circle, since having one may dramatically increase the risk of developing the other. Additionally, this unfortunate connection makes individuals socially isolated $[26,27]$. Though these two complex phenomena share common characteristics, the nature of this relation remains unclear. Indeed, they both affect physical, emotional, cognitive and behavioral domains of human life.
An overlap in symptoms is frequently observed, but patients with chronic fatigue lack feelings of anhedonia, guilt, and decreased motivation which are typically seen in patients with depression [15]. Patients with chronic fatigue show similar motor impairment to those with depression [28]. Approximately, two thirds of patients having chronic fatigue also present signs of major depression. Both anxiety and depression may affect levels of fatigue in various ways. Individuals with depression lack motivation or energy to perform either physical or mental tasks, and they frequently experience changes in sleep patterns, which in turn increase levels of fatigue [29]. On the other end of the spectrum, anxiety makes individuals more vulnerable to panic, fear and other high-stress responses which successively increase levels of fatigue. Anxiety frequently co-exists with depression [26].

In conclusion, high levels of anxiety and depression were observed in women, participants with primary education, those who described themselves as anxious, who were very anxious about their heart rate and the proper functioning of the device, those who had help with their daily activities, those who believed that the pacemaker does not solve the problem of arrhythmia, those who did not believe that their quality of life was improved, those who did not smoke and finally participants who had experienced symptoms.

It is widely accepted that the pacemaker is an opportunity to prolong patients' survival. Notwithstanding, it needs routine follow-up along with the systematic evaluation of anxiety and depression and consultation with psychiatrists.

This research illustrates the association between fatigue and anxiety/depression and contributes to identifying associated factors. The findings may help health care professionals to provide holistic care by implementing appropriate strategies to alleviate this burden and help patients manage to live with this device.

Future research might involve a group of patients in pre-implantation and post-implantation phases with a follow-up of one or more years afterwards. Research material on pacemaker patients in Greece is limited, so future research efforts may shed more light on this sensitive population and the burden of their physical emotions.

\section{Acknowledgments}

This postdoctoral research was conducted in the Department of Nursing, Faculty of Human Movement and Quality of Life Sciences, University of Peloponnese, Sparta Lakonias, Greece. We would like to show our gratitude to George Panoutsopoulos for sharing his wisdom and his clinical expertise with us during the course of this research. 


\section{Conflict of interest}

The authors declare no conflict of interest.

\section{References}

1. Brunner M, Olschewski M, Geibel A, Bode C, Zehender M. Long-term survival after pacemaker implantation. Prognostic importance of gender and baseline patient characteristics. Eur Heart J 2004; 25: 88-95.

2. Ghojazadeh M, Azami Aghdash S, Sohrab Navi Z, Kolahdouzan K. Cardiovascular patients' experiences of living with pacemaker: qualitative study. ARYA Atheroscler 2015; 11: 281-8.

3. Uslan DZ, Tleyjeh IM, Baddour LM, et al. 2008 Temporal trends in permanent pacemaker implantation: a population-based study. Am Heart J 2008; 896-903.

4. Vellone E, Rega ML, Galletti C, Morchio A, Alvaro R, Sansoni J. Anxiety and depression before and after a pacemaker implantation: a comparative study. Int Nurs Persp 2008; 8: 93-9.

5. Bradshaw PJ, Stobie P, Knuiman MV, Briffa TG, Hobbs MS. Life expectancy after implantation of a first cardiac permanent pacemaker (1995-2008): a population-based study. Int J Cardiol 2015; 190: 42-6.

6. Iliou MC, Blanchard JC, Lamar Tanguy A, Cristofini P, Ledru F. Cardiac rehabilitation in patients with pacemak ers and implantable cardioverter defibrillators. Monaldi Arch Chest Dis 2016; 86: 756

7. Lampert R. Managing with pacemakers and implantable cardioverter defibrillators. Circulation 2013; 128: 1576-85.

8. Duru F, Büchi S, Klaghofer R, et al. How different from pacemaker patients are recipients of implantable cardioverter-defibrillators with respect to psychosocial adaptation, affective disorders, and quality of life? Heart 2001; 85: 375-9.

9. Leone St. A disabling combination: fatigue and depression. Br J Psychiatry 2010; 197: 86-7.

10. Zigmond AS, Snaith RP. The Hospital Anxiety And Depression Scale. Acta Psychiatr Scand 1983; 67: 361-70.

11. Mystakidou K, Tsilika E, Parpa E, Katsouda E, Galanos A, Vlahos L. The Hospital Anxiety and Depression Scale in Greek cancer patients: psychometric analyses and applicability. Support Care Cancer 2004; 12: 821-5.

12. Zyga S, Alikari V, Sachlas A, et al. Assessment of fatigue in end stage renal disease patients undergoing hemodialysis: prevalence and associated factors. Med Arh 2015; 69: 376-80

13. Ozcan C, Jahangir A, Friedman PA, et al. Long-term survival after ablation of the atrioventricular node and implantation of a permanent pacemaker in patients with atrial fibrillation. N Engl J Med 2001; 344: 1043-51.

14. Aydemir O, Ozmen E, Küey L, et al. Psychiatric morbidity and depressive symptomatology in patients with permanent pacemakers. Pacing Clin Electrophysiol 1997; 20: $1628-32$.

15. Goodwin GM. Depression and associated physical diseases and symptoms. Dialogues Clin Neurosci 2006; 8: 259-65.

16. Wood MA, Ellenbogen KA. Cardiology patient pages. Cardiac pacemakers from the patient's perspective. Circulation 2002; 105: 2136-8.

17. Hart PL. Women's perceptions of coronary heart disease: an integrative review. J Cardiovasc Nurs 2005; 20: 170-6.

18. Lockyer L. Women's interpretation of their coronary heart disease symptoms. Eur J Cardiovasc Nurs 2005; 4: 29-35.
19. Altemus M, Sarvaiya N, Epperson CN. Sex differences in anxiety and depression clinical perspectives. Front Neuroendocrinol 2014; 35: 320-30.

20. Toogood G. Pacemaker therapies in cardiology. Aust Fam Physician 2007; 36: 518-9, 521-4

21. Malm D, Hallberg LR. Patients' experiences of daily living with a pacemaker: a grounded theory study. J Health Psychol 2006; 11: 787-98.

22. Malm D, Karlsson JE, Fridlund B. Effects of a self-care program on the health-related quality of life of pacemaker patients: a nursing intervention study. Can J Cardiovascular Nurs 2007; 17: 15-26.

23. Polikandrioti M, Goudevenos J, Michalis L, et al. Correlation between the type of acute coronary syndrome with the needs of hospitalized patients. Glob J Health Sci 2016; 8: 126-8.

24. Aqeel M, Shafquat A, Salahuddin N. Pacemaker patients' perception of unsafe activities: a survey. BMC Cardiovascular Disorders 2008; 8: 31.

25. Xhulia D, Gerta J, Dajana Z, et al. Needs of hemodialysis patients and factors affecting them. Glob J Health Sci 2016; 8: 109-20.

26. Ballenger JC. Anxiety and depression: optimizing treatments. Prim Care Companion J Clin Psychiatry 2000; 2: 71-9.

27. Addington AM, Gallo JJ, Ford DE, Eaton WW. Epidemiology of unexplained fatigue and major depression in the community: the Baltimore ECA follow-up, 1981-1994. Psychol Med 2001; 31: 1037-44.

28. Lawrie SM, MacHale SM, Cavanagh JT, O'Carroll RE, Goodwin GM. The difference in patterns of motor and cognitive function in chronic fatigue syndrome and severe depressive illness. Psychol Med 2000; 30: 433-42.

29. Craig T, Kakumanu S. Chronic fatigue syndrome: evaluation and treatment. Am Fam Physician 2002; 65: 1083-90. 